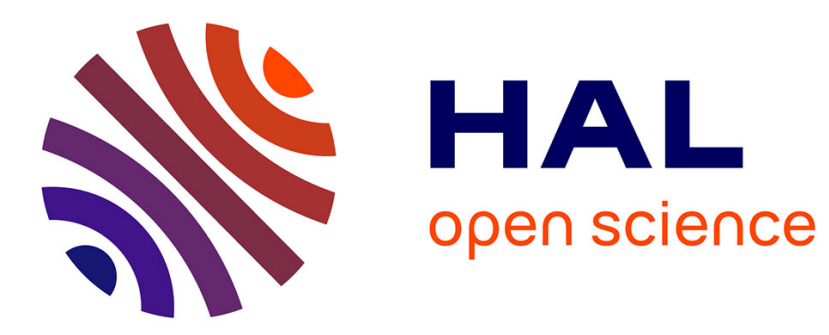

\title{
Food addiction in bariatric surgery candidates: prevalence and risk factors
}

\author{
Paul Brunault, Pierre-Henri Ducluzeau, Céline Bourbao-Tournois, Irène \\ Delbachian, Charles Couet, Christian Réveillère, Nicolas Ballon
}

\section{- To cite this version:}

Paul Brunault, Pierre-Henri Ducluzeau, Céline Bourbao-Tournois, Irène Delbachian, Charles Couet, et al.. Food addiction in bariatric surgery candidates: prevalence and risk factors. Obesity Surgery, 2016, 26 (7), pp.1650-1653. 10.1007/s11695-016-2189-x . hal-01379530

\section{HAL Id: hal-01379530 \\ https://hal.science/hal-01379530}

Submitted on 12 Oct 2016

HAL is a multi-disciplinary open access archive for the deposit and dissemination of scientific research documents, whether they are published or not. The documents may come from teaching and research institutions in France or abroad, or from public or private research centers.
L'archive ouverte pluridisciplinaire HAL, est destinée au dépôt et à la diffusion de documents scientifiques de niveau recherche, publiés ou non, émanant des établissements d'enseignement et de recherche français ou étrangers, des laboratoires publics ou privés. 
Authors: Paul Brunault ${ }^{1,2,3,4}$, Pierre-Henri Ducluzeau ${ }^{4,5,6,7}$, Céline Bourbao-Tournois ${ }^{4,8}$, Irène Delbachian $^{4,5}$, Charles Couet ${ }^{4,5,6,7}$, Christian Réveillère ${ }^{3}$, Nicolas Ballon $^{1,2,4,9}$

Title: Food addiction in bariatric surgery candidates: prevalence and risk factors

${ }^{1}$ CHRU de Tours, Équipe de Liaison et de Soins en Addictologie, Tours, France

${ }^{2}$ CHRU de Tours, Clinique Psychiatrique Universitaire, Tours, France

${ }^{3}$ Université François Rabelais de Tours, Département de Psychologie, EA 2114 «Psychologie des Âges de la Vie », Tours, France.

${ }^{4}$ CHRU de Tours, Centre Spécialisé pour la prise en charge de l'Obésité sévère, Tours, France

${ }^{5}$ CHRU de Tours, Service de Médecine Interne-Nutrition, Tours, France

${ }^{6}$ Université François Rabelais de Tours, Inserm U 1069, Tours, France

${ }^{7}$ Université François Rabelais de Tours, Tours, France

${ }^{8}$ CHRU de Tours, Service de Chirurgie Digestive et Endocrinienne, Tours, France

${ }^{9}$ Université François Rabelais de Tours, UMR INSERM U930 « Imagerie et Cerveau », Tours, France

\section{Correspondingauthor:}

Paul Brunault, CHRU de Tours, Clinique Psychiatrique Universitaire, 2 boulevard Tonnellé, 37000 Tours, France.

e-mail address: paul.brunault@univ-tours.fr

Telephone: +33-247-478043; Fax: +33-247-478402

Short title: Food addiction in bariatric surgery candidates

Grant information: This study was conducted without specific funding.

Keywords:Obesity; Bariatric surgery; Addictive Behaviors; Food Addiction; Quality of Life ; Binge-Eating Disorder ; Depression

This is the postprint version (final draft post refereeing) of the following article: "Paul Brunault, Pierre-Henri Ducluzeau, Céline Bourbao-Tournois, IrèneDelbachian, Charles Couet, Christian Réveillère, Nicolas Ballon(2016). Food addiction in bariatric surgery candidates: prevalence and risk factors. Obesity Surgery; 2016 Jul;26(7):1650-3.doi: 10.1007/s11695-016-2189-x.”, which has been published in final form at:http://link.springer.com/article/10.1007\%2Fs11695-016$\underline{\text { 2189-x }}$ 


\begin{abstract}
This study assessed the prevalence and risk factors for food addiction (FA) in bariatric surgery candidates. We assessed BMI, FA (Yale Food Addiction Scale), quality of life (Quality Of Life, Obesity and Dietetics), depression (Beck Depression Inventory), and binge eating (Binge Eating Scale) in 188 obese patients. The most prevalent addiction criteria were persistent desire to control food consumption (93.1\%), continuing to eat certain foods despite problems (40.4\%), and tolerance (38.8\%); current prevalence of FA was $16.5 \%$. Patients with (vs. without) FA were more often single, had lower physical, psycho-social and sexual quality of life, and higher depression and binge eating. Systematic screening for and treatment of FA symptoms before obesity surgery is critical because FA symptoms are prevalent and associated with poorer psychosocial outcome.
\end{abstract}




\section{INTRODUCTION}

Bariatric surgery is an efficient treatment for severe obesity, associated with long-term weight loss and improvement in comorbidities and quality of life (QoL) [1,2]. Due to variations in postoperative outcomes [2], current research aims to determine, screen for and treat the factors associated with poor postoperative outcomes. Pre- and post-operative eating disorders and problematic eating behavior are important factors affecting postoperative QoL, comorbidities, and sometimes weight loss [2]. To date, studies of eating behavior in bariatric surgery patients have focused on Binge Eating Disorder (BED), the most prevalent form of eating disorder in obese patients, affecting from 5 to $50 \%$ of bariatric surgery candidates [2,3]. BED is characterized by recurrent binge eating (i.e., consumption of unusually large amounts of food during a discrete period of time, while experiencing a sense of loss of control) without compensatory weight control behaviors[4].

To identify specific aspects of food addiction in patients exhibiting significant distress in relation to food, Gearhardt et al. adapted the DSM diagnostic criteria for substance dependence to addiction to certain foods, particularly highly processed foods high in added sugar, fat and salt [5]. Food addiction describes the behavior of the subpopulation of patients who show substancedependence symptoms in their eating behavior (i.e., diminished control over food consumption; consumption despite adverse physical or psychological consequences; persistent desire or unsuccessful efforts to cut down or control food use; eating in larger amount or over longer period than intended; giving up important occupational or recreational activities because of food consumption; tolerance; withdrawal; significant distress in relation to food) [5]. This definition is complementary to BED, making it possible to screen patients who experience significant distress in relation to food or loss of control over their eating behavior but do not meet the diagnostic criteria for BED (i.e., consumption of small or moderate amounts of food throughout the day; consumption of food over a long period of time; continuation of eating behavior despite physical or psychological problems). There is growing evidence for the clinical validity and utility of the concept of food addiction in obese patients: food addiction is highly prevalent in obese patients [6] and sometimes associated with poorer weight loss [7]. However, few studies have focused on bariatric surgery candidates, and there is a lack of studies examining the biological and psychological characteristics of food addiction in this population [6].

This study aimed to assess the prevalence of food addiction in bariatric surgery candidates and to determine their biological (age, gender, BMI, duration and age of onset of obesity) and psychological (i.e., QoL, depression, binge eating) characteristics. We hypothesized that food addiction would be more prevalent in bariatric surgery candidates than in the overall population and associated with poor psychosocial outcome (i.e., low QoL and high levels of depression and binge eating). 


\section{MATERIALS AND METHODS}

\section{Participants and procedure}

This cross-sectional study included all consecutive bariatric surgery candidates seen in the Nutrition Department of the University Hospital of Tours (France) and referred for preoperative psychiatric assessment between July 2013 and November 2015. Out of the initial population $(n=204), 16$ were excluded (10 did not understand the questionnaires and 6 gave incomplete data), leading to a final sample of 188 patients. Patients answered the questionnaires shortly before the systematic preoperative psychiatric consultation.

\section{Measures}

We collected data on demographics (age, gender, marital status), current body-mass index (BMI), previous maximal BMI, age of onset and duration of obesity.

We diagnosed current food addiction using the French version of the Yale Food Addiction Scale $[8,9]$, that assesses the seven diagnostic criteria for food addiction based on the DSM-IV-TR diagnostic criteria for substance dependence as well as significant distress in relation to food. Food addiction was diagnosed when at least three of the seven symptoms were present during the previous 12 months and clinically significant impairment or distress was confirmed [5].

We assessed physical, psycho-social and sexual QoL using the 'Quality Of Life, Obesity and Dietetics' (QOLOD) rating scale [10], which is a French tool derived from the 'Impact of Weight on Quality Of Life Questionnaire', the first instrument specifically designed to assess QoL in obesity.

We assessed depression using the shortened Beck Depression Inventory, a widely used 13item self-rating scale (cut-off $\geq 16$ ) [11] used in bariatric surgery populations.

We assessed binge eating symptoms using the Binge Eating Scale, a 16-item self-report scale (cutoff $\geq 18$ ), which is a reliable screening tool for BED in obese patients [12].

\section{Statistical analyses}

Analyses were conducted using SPSS version 22 (IBM Corp. Released 2013. IBM SPSS Statistics for Windows, Version 22.0. Armonk, NY: IBM Corp.). We used mean comparison tests (Mann Whitney U test or Student's test based on the assumption of normality of the variables) and chi-squared tests (we checked that theoretical frequencies were higher or equal to 5 for each cell and for each analysis) to compare patients with and without food addiction.

\section{RESULTS}

\section{Descriptive data (Table 1)}

Table 1 presents the characteristics of the overall population, including patients with and without food addiction. Mean age was $40.8 \pm 12.6$ years; $84 \%$ were female. Prevalence of current food addiction was $16.5 \%$ (significantly higher than the $8.7 \%$ prevalence observed in the overall population[9]; 
$\mathrm{p}<.001)$. In our sample, the most prevalent food addiction symptoms were, by order of importance: persistent desire to control consumption of certain foods (93.1\%), continuing to eat certain foods despite physical or psychological problems $(40.4 \%)$, tolerance $(38.8 \%)$, considerable time spent to obtain, use, or recover from the effects of certain foods (25\%), significant distress in relation to these foods $(22.9 \%)$, use of food in larger quantities or over longer periods than intended (18.6\%), withdrawal (14.4\%), and giving up important activities because of food (13.3\%).

\section{Comparison of patients with and without food addiction (Table 1)}

Patients with food addiction were more frequently single than those without, but there was no difference in terms of age, gender, current BMI, previous maximal BMI, duration of obesity, or age of onset of obesity.

Patients with food addiction reported lower physical, psycho-social and sexual QoL, and higher prevalence and levels of depression and binge eating than those without addiction. Thirty-six percent of the patients with food addiction had no significant binge eating.

\section{CONCLUSION}

This study demonstrated that food addiction is very prevalent among bariatric surgery candidates (16.5\%) and higher than in the overall population (8.7\%), with a high prevalence rate for each food addiction criterion (especially "persistent desire to control consumption of certain foods", "continuing to eat certain foods despite physical or psychological problems" and "tolerance"). Patients with food addiction experienced lower QoL, and higher levels of depression and binge eating.

In view of the low QoL and the high comorbidity with psychiatric disorders in patients with food addiction, better screening and treatment of this condition is crucial during the preoperative period, as persistence of addiction could partly explain the persistence of psychiatric disorders. Given that it is generally easier to report one's addiction symptoms than one's psychiatric symptoms (i.e., psychiatric disorders are more stigmatized than addictions), screening for food addiction could also help identify this high-risk subpopulation (i.e., greater psychopathology and lower QoL).

We confirmed that binge eating and food addiction are distinct constructs (36\% of patients with food addiction had no significant binge eating), demonstrating that the simultaneous assessment of BED and food addiction could improve our ability to identify patients who exhibit problematic eating behavior, compared to considering BED alone.

Finally, given that addictions share some specific risk factors, patients with food addiction may have a higher risk of switching to another addiction after surgery if not treated (we assume that this might explain the postoperative increase in alcohol addiction).

Our study's limitations include the small sample size, the cross-sectional design, and the use of self-administered scales. Although we demonstrated that food addiction was associated with poorer preoperative psychosocial outcome in bariatric surgery candidates, future studies should determine its 
association with postoperative outcomes (could pre- or post-operative food addiction be a risk factor for lower weight loss, lower QoL, and/or higher prevalence of postoperative comorbidities?).

Food addiction is concept that might be of importance in bariatric surgery patients because of its prevalence and because of its potential association with long-term postoperative outcome. If confirmed, it would lead to novel management and treatment strategies that might improve postoperative outcome.

Conflict of Interest Statement: Dr. Brunault reports personal fees and non-financial support from Lundbeck, personal fees from Astra-Zeneca, personal fees from DNA Pharma, outside the submitted work. Pr. Ballon reports personal fees from Lundbeck, personal fees from Astra-Zeneca, personal fees from DNA Pharma, outside the submitted work. Pr. Ducluzeau, Dr. Bourbao-Tournois, Dr. Delbachian, Pr. Couet and Pr. Réveillère have nothing to disclose.

Ethical approval: All procedures performed in studies involving human participants were in accordance with the ethical standards of the 1964 Helsinki declaration and its later amendments or comparable ethical standards.

Informed consent: Informed consent was obtained from all individual participants included in the study.

We thank Elizabeth Yates for correcting the English version of the manuscript. 


\section{REFERENCES}

1. Buchwald H, Avidor Y, Braunwald E, Jensen MD, Pories W, Fahrbach K, et al. Bariatric surgery: a systematic review and meta-analysis. JAMA. 2004;292(14):1724-37.

2. van Hout G, van Heck G. Bariatric psychology, psychological aspects of weight loss surgery. Obes Facts. 2009;2(1):10-5.

3. Niego SH, Kofman MD, Weiss JJ, Geliebter A. Binge eating in the bariatric surgery population: a review of the literature. Int J Eat Disord. 2007;40(4):349-59. 4. American Psychiatric Association. Diagnostic and Statistical Manual of Mental Disorders, Fifth Edition.Arlington, VA, American Psychiatric Association, 2013.

5. Gearhardt AN, Corbin WR, Brownell KD. Food addiction: an examination of the diagnostic criteria for dependence. J Addict Med. 2009;3(1):1-7.

6. Meule A, Gearhardt AN. Five years of the Yale Food Addiction Scale: Taking stock and moving forward. Curr Addict Rep. 2014;1(3):193-205.

7. Burmeister JM, Hinman N, Koball A, Hoffmann DA, Carels RA. Food addiction in adults seeking weight loss treatment. Implications for psychosocial health and weight loss. Appetite. 2013;60(1):103-10.

8. Gearhardt AN, Corbin WR, Brownell KD. Preliminary validation of the Yale Food Addiction Scale. Appetite. 2009;52(2):430-6.

9. Brunault P, Ballon N, Gaillard P, Réveillère C, Courtois R. Validation of the French version of the Yale Food Addiction Scale: an examination of its factor structure, reliability, and construct validity in a non clinical sample. Can J Psychiatry. 2014;59(5):276-84.

10. Ziegler O, Filipecki J, Girod I, Guillemin F. Development and validation of a French obesityspecificquality of life questionnaire: Quality of Life, Obesity and Dietetics (QOLOD) rating scale. Diabetes Metab. 2005;31(3):273-83.

11. Beck AT, Steer RA, Garbin MG. Psychometric properties of the Beck Depression Inventory: twenty-five years of evaluation. Clin Psychol Rev. 1988;8(1):77-100.

12. Gormally J, Black S, Daston S, Rardin D. The assessment of binge eating severity among obese persons. Addict Behav. 1982;7(1):47-55. 


\section{TABLES}

Table 1.Descriptive statistics of the overall population, and comparison of patients with and without food addiction.

\begin{tabular}{|c|c|c|c|c|}
\hline & $\begin{array}{l}\text { Overall } \\
\text { population } \\
(n=188)\end{array}$ & $\begin{array}{c}\text { Patients } \\
\text { without food } \\
\text { addiction } \\
(n=157)\end{array}$ & $\begin{array}{l}\text { Patients with } \\
\text { food addiction } \\
\qquad(n=31)\end{array}$ & $p$ \\
\hline \multicolumn{5}{|l|}{ Sociodemographic characteristics } \\
\hline Age (years) & $40.8 \pm 12.3$ & $40.6 \pm 12.2$ & $42.1 \pm 12.7$ & 0.54 \\
\hline Gender (female) & $84.0 \%(158)$ & $82.8 \%(130)$ & $90.3 \%(28)$ & 0.30 \\
\hline Marital status (married or in a relationship)* & $69.1 \%(130)$ & $72.6 \%(114)^{*}$ & $51.6 \%(16)^{*}$ & $<0.05$ \\
\hline \multicolumn{5}{|l|}{ Weight-related variables } \\
\hline Weight (kg) & $124.9 \pm 24.9$ & $126.0 \pm 25.7$ & $119.3 \pm 19.7$ & 0.25 \\
\hline $\operatorname{BMI}\left(\mathrm{kg} / \mathrm{m}^{2}\right)$ & $46.0 \pm 7.3$ & $46.4 \pm 7.6$ & $43.9 \pm 4.8$ & 0.15 \\
\hline Previous maximal BMI $\left(\mathrm{kg} / \mathrm{m}^{2}\right)$ & $48.8 \pm 7.9$ & $49.3 \pm 8.3$ & $46.4 \pm 5.2$ & 0.14 \\
\hline Age of onset of obesity (years) & $17.7 \pm 12.2$ & $17.4 \pm 12.3$ & $19.6 \pm 11.7$ & 0.36 \\
\hline Duration of obesity (years) & $23.7 \pm 11.3$ & $24.0 \pm 11.1$ & $22.5 \pm 12.6$ & 0.52 \\
\hline Food addiction (prevalence) & $16.5 \%$ & - & - & - \\
\hline \multicolumn{5}{|l|}{ Food addiction symptoms (prevalence) } \\
\hline Tolerance*** & $38.8 \%(73)$ & $33.8 \%(53) * * *$ & $64.5 \%(20) * * *$ & $<0.001$ \\
\hline Withdrawal*** & $14.4 \%(27)$ & $7.6 \%(12)^{* * *}$ & $45.4 \%(15)^{* * *}$ & $<0.001$ \\
\hline \multicolumn{5}{|l|}{ Food consumed in larger quantities or over a } \\
\hline longer period than intended $* * *$ & $18.6 \%(35)$ & $11.5 \%(18)^{* * *}$ & $54.8 \%(17)^{* * *}$ & $<0.001$ \\
\hline $\begin{array}{l}\text { Persistent desire or unsuccessful efforts to cut } \\
\text { down or control consumption of certain foods }\end{array}$ & $93.1 \%(175)$ & $92.4 \%(145)$ & $96.8 \%(30)$ & 0.38 \\
\hline $\begin{array}{l}\text { Considerable time spent to obtain, consume, } \\
\text { or recover from effects of food } * * *\end{array}$ & $25 \%(47)$ & $17.8 \%(28) * * *$ & $61.3 \%(19)^{* * *}$ & $<0.001$ \\
\hline $\begin{array}{l}\text { Giving up important social, occupational, or } \\
\text { recreational activities because of food } \\
\text { consumption*** }\end{array}$ & $13.3 \%(25)$ & $6.4 \%(10)^{* * *}$ & $48.4 \%(15)^{* * *}$ & $<0.001$ \\
\hline $\begin{array}{l}\text { Continuing to eat certain foods despite } \\
\text { physical or psychological problem*** }\end{array}$ & $40.4 \%(76)$ & $33.1 \%(52) * * *$ & $77.4 \%(24) * * *$ & $<0.001$ \\
\hline Significant distress in relation to food $* * *$ & $22.9 \%(43)$ & $7.6 \%(12)^{* * * *}$ & $100 \%(31)^{* * *}$ & $<0.001$ \\
\hline \multicolumn{5}{|l|}{ Quality of life } \\
\hline Physical quality of life $* * *$ & $33.1 \pm 9.2$ & $34.4 \pm 8.9 * * *$ & $26.7 \pm 8.3 * * *$ & $<0.001$ \\
\hline Psychosocial quality of life $* * *$ & $34.7 \pm 9.7$ & $36.3 \pm 26.1 * * *$ & $26.1 \pm 8.3 * * *$ & $<0.001$ \\
\hline Sexual quality of life $* * *$ & $13.7 \pm 4.8$ & $14.3 \pm 4.6^{* * *}$ & $10.7 \pm 4.8^{* * *}$ & $<0.001$ \\
\hline \multicolumn{5}{|l|}{ Depression } \\
\hline Mean BDI score*** & $8.1 \pm 6.1$ & $6.9 \pm 5.1 * * *$ & $14.1 \pm 7.4 * * *$ & $<0.001$ \\
\hline Significant BDI score $* * *$ & $11.7 \%(22)$ & $7.0 \%(11)^{* * *}$ & $35.5 \%(11)^{* * *}$ & $<0.001$ \\
\hline \multicolumn{5}{|l|}{ Binge eating } \\
\hline Mean BES score*** & $11.0 \pm 7.9$ & $9.0 \pm 6.1$ & $21.3 \pm 8.1$ & $<0.001$ \\
\hline Significant BES score $* * *$ & $17.0 \%(32)$ & $7.6 \%(12)^{* * *}$ & $64.5 \%(20)^{* * *}$ & $<0.001$ \\
\hline
\end{tabular}

Legends: Descriptive data are presented as mean \pm standard deviation or percentage (number). We compared patients with and without food addiction using mean comparison tests (Mann Whitney U test or Student's test) and chi-squared tests.*, ** and *** indicate variables significantly associated with food addiction diagnosis $(*$ $\mathrm{p}<0.05$; ** $\mathrm{p}<0.01$; *** $\mathrm{p}<0.001)$. BMI: Body Mass Index; BDI: Beck Depression Inventory; BES: Binge Eating Scale. 